\title{
Injury Risk and Maturity Status in Italian Elite Young Football Player
}

\author{
S. Toselli ${ }^{1}$, L. Benedetti ${ }^{2}$, R. Di Miceli ${ }^{3}$, P. Aiello ${ }^{2}$, G. Nanni ${ }^{3}$ \\ 1 Department of Biomedical and Neuromotor Sciences, University of Bologna, Bologna, Italy \\ 2 Bologna F.C. 1909 Technical Center, Bologna, Italy \\ 3 Isokinetic Research Center, Bologna, Italy
}

\author{
CORRESPONDING AUTHOR: \\ Benedetti Luca \\ Bologna F.C. 1909 Technical Center \\ via Righi Riva 33 \\ Modena, Italy \\ E-mail: lucaben759@gmail.com
}

DOI:

10.32098/mltj.03.2021.25

LEVEL OF EVIDENCE: 2B

\section{SUMMARY}

Background. Football is one of the world's most popular sport with most players being younger than 18 years. Playing football can induce beneficial health effects in youth, but there is also a high risk of injury. In young football players, the relationship between injury risk in the different periods from peak height velocity (PHV) remains unclear. The objective of the study was to investigate the associations between the injury risk and injury burden in young Italian football players in different periods from PHV (pre-PHV, PHV and Post-PHV).

Methods. One hundred and forty-one young players (age $=13.9 \pm 0.8$ years) were subdivided in three groups on the basis of maturity status: PHV was set by taking 6 months before and 6 months after the age at PHV; the 12 months before this year were allocated as the year before PHV (Pre-PHV); the 12 months after this year were allocated as the year after PHV (Post-PHV).

The number of injuries was calculated for each player per year; injuries were classified by location, type, body-site and mechanism of injury (traumatic or overuse). Training and match injury incidence was also calculated and resulted $4.2 \pm 6.9$ per $1000 \mathrm{~h}$ and $10.0 \pm 34.2$ per $1000 \mathrm{~h}$, respectively.

Results. In total 25214 hours of exposure were recorded. A total of 83 injuries were reported. Most injuries (77\%) were located in the lower limbs; the most common injuries were joint/ligament injuries $(36 \%)$.

Traumatic injury showed a tendency to increase from the year before PHV to the year of PHV, and after this period a decrease can be observed; while, overuse injuries incidence remains constant until PHV, and then decreased in the year after PHV, albeit the differences were not statistically significant. A non-significant higher training injury incidence was found at PHV, while match injury incidence was higher at Pre-PHV. Days missed due to injury show an increase up to PHV, and then a considerable decrease in the year after PHV; the difference among groups were statistically significant $(p=0.039)$; moreover, the effect size between PHV and Post-PHV was moderate. The mean of exposure shows a significant increase from the year before PHV to the year after PHV ( $p=0.0089)$, furthermore, the effect size between Pre-PHV and PostPHV was large.

Conclusions. The results of this study on young Italian football players confirm the overall increased vulnerability of the athletes in the PHV period. Great attention should be given to the maturity status of the subjects. To try to limit injuries, training programs should be calibrated on the state of maturity of the players and not on their chronological age.

\section{KEY WORDS}

Adolescent; biological age; individualized loads; trauma; youth sport. 


\section{BACKGROUND}

Soccer is a complex contact sport that involves relatively high risks and rates of injury at all levels (young athletes, amateur, and professional), during training and match. A specific attention needs to be paid to sport injuries in youth athletes since it is very common for them to encounter an injury during competitive season, which determines restricted participation or training modifications and often a long time of absence from normal training (1). This, as a consequence, imply a substantial reduction of the chances of reaching high levels of performance (2).

As regards the nature and incidence of injuries in young soccer players, precise conclusions are difficult to draw from the available literature (3). Injury represents a central topic for sport science, where is thus fundamental to acquire a clear framework about injury risk factors, to the aim of planning preventive strategies.

The adolescence represents a sensitive phase, in which a great variability in growth and maturation is observed between individuals. Growth rates show a significant increase during the adolescent growth spurt, with the peak height velocity (PHV) observed in average from 13 to 14 years in boys, although with a certain inter-individual variability (4). PHV can be reached at different age, since individuals present a great variation the timing and tempo of biological maturation, so that within a specific age class it is possible to find subjects in different maturation stage, which can be classified as early, average or late maturers.

The difference in biological maturation and the discrepancies in size and performance observed in youth who play sports are the subject of great discussions regarding competitive disadvantages and the risk of injury. The rapid growth and, as a consequence, the period around PHV have been generally associated with an increased risk of injury in elite youth athletes, (5) even if not all studies agree $(6,7)$. The higher incidence at PHV has been interpreted as being due to the reduction of the concentration of bone mineral, increased tensile forces on vulnerable muscle attachments, decreased neuromuscular control and reduced flexibility that occurs in this period $(4,5,8)$.

These factors combined with excessive functional overload result in an inflammatory degenerative process that can cause injury. Injuries are of two types: traumatic and overuse injuries. Muscle injuries, joint dislocations and bone fractures are considered acute traumatic injuries. This type of trauma is generally due to a single event, which exceeds the resistance capacity of the structure, generating an injury $(5,6,9)$. Chronic pathologies due to functional overload, therefore microtraumas that recur over time, are defined as overuse injuries (10). Somato-anthropometric changes and changes in body composition have been identified among the possible causes of overuse injuries (8). Studies investigating the etiology of growing-up injuries in young players have documented that the majority of overuse injuries caused an absence from play of more than 28 days (severe injury) $(8,11)$. Most of the functional overload injuries recorded in the literature were Osgood Schlatter and Sinding Larsen Johansson syndrome, caused by excessive overload of the myotendon complex and highly associated with growth. Microtraumas are observed not only in the muscle-tendon system, but also in the bone, cartilage and ligament (12). Non-individualized loads bring excessive overload to the anatomical structures mentioned above, generating a degenerative-inflammatory process that is at the basis of overuse injuries. This happens very frequently in the elite youth sectors, where incorrect load management combined with excessively intensive training can cause overuse injuries $(3,6)$.

Traumatic and overuse injuries occur mainly during PHV and this may be due to a double factor: the first of a mechanical nature, namely the functional overload imposed on the structure; the second of a physiological nature, since the bone tissue and the myotendon complex which are developing during the PHV cannot tolerate high forces; therefore, an overload combined with excessive shear and compression forces on the previously mentioned tissues can cause trauma.

Having found in the literature a lack of uniformity about the peaks of incidence of the different types of injuries, it is necessary to proceed with further investigations. In addition, no data are at disposal for Italian elite young football player. The aim of the present study was to analyze differences in the incidence of injuries in Italian young elite soccer players belonging to different maturation stage (pre-PHV, PHV and post-PHV) in order to identify the relationship between injuries (traumatic and overuse) and maturity.

\section{MATERIALS AND METHODS}

This cross-sectional study included 141 elite male youth soccer players (age 13.9 \pm 0.8 ) from the U13-U15 categories (U13, $\mathrm{N}=26 ; \mathrm{U} 14, \mathrm{~N}=64 ; \mathrm{U15}, \mathrm{N}=51$ ), associated with an Italian Serie A professional soccer team (Bologna F.C. 1909). Participants were selected from the season 2018/2019. The eligibility criteria for this study were athletes who had been playing for at least a full season and were to be in one of the following maturity stages: 1 year before, 1 year during and 1 year after their predicted PHV. The players voluntarily decided to participate, and their parents provided informed consent after a detailed description of the study procedures. The study was carried out in conformity with the ethical standards laid down in the 1975 declaration of Helsinki 
and was approved by the local Bioethics Committee of the University of Bologna (Approval Code: 25027) and were in accordance with the MLTJ guidelines (13).

All anthropometric data were collected by a specifically trained physician. Height, sitting height, body weight were collected with participants wearing only shorts. Height and sitting height were recorded to the nearest $0.1 \mathrm{~cm}$ with a standing stadiometer (Raven Equipment Ltd. Great Donmow, UK) and body weight was measured to the nearest $0.1 \mathrm{~kg}$ with a high-precision mechanical scale (Seca, Basel, Switzerland). Leg length was derived as the difference between height and sitting height. An estimation of the years from peak height velocity (YPHV), which is an indicator for the adolescent growth spurt, was made using Mirwald's equation for boys, which can predict maturity offset in youth athletes $(14,15)$. Maturity offset $=-9.236$ +0.0002708 (leg length $\times$ sitting height) -0.001663 (age $\times$ leg length $)+0.007216($ age $\times$ sitting height $)+0.02292$ (weight: height). Since maturity offset represents the years of distance from peak height velocity (PHV), predicted age at PHV (years) was calculated as the difference between chronological age and maturity offset.

To compare injuries between players of different maturation status, the year of PHV was set by taking 6 months before and 6 months after the age at PHV. The 12 months before this year were allocated as the year before PHV (Pre-PHV); the 12 months after this year were allocated as the year after PHV (Post-PHV). Based on these classifications the subjects were divided into three groups: Pre-PHV, $\mathrm{N}=51$; PHV, $\mathrm{N}=81$; Post-PHV, $\mathrm{N}=31$ (5).

Injuries have been recorded and diagnosed by the medical staff of the team. According to the consensus statement for soccer injury studies, i.e., the FIFA registration system (10), an injury was defined as: "any physical complaint sustained by a player that results from a football match or football training, irrespective of the need for medical attention or time loss from football activities". The physician recorded "time-loss" injury that results in a player being unable to take a full part in future football training or match the injuries.

Injuries can be classified by location, type, body-site and mechanism of injury (traumatic or overuse). Traumatic injuries refer to "an injury resulting from a specific, identifiable event"; while overuse injuries are caused by repeated micro-trauma without a single, identifiable event responsible for the injury.

The location of injuries is divided in four main groups: head and neck, upper limbs, trunk and lower limbs. The type of injuries is recorded in 6 main groups: fracture and bone stress, joint and ligament, muscle and tendon, contusions, center / peripheral nervous system and other. The severity of the injury was defined as the number of days that the player was not able to take full part in competition or training: minimal (1-3 days' time loss), mild (4-7 days' time loss), moderate (8-28 days' time loss), severe (more than 28 days' time loss). The hours of training and matches were recorded by the athletic trainers of the respective categories. In case of missing data, training and match hours were replaced by the average amount of training hours or match hours for the corresponding age category in that year. Traumatic and overuse injuries was calculated as the number of injuries per $1000 \mathrm{~h}$ of total exposure (training exposure plus match exposure); training and match injury incidence was calculated as the number of injuries per $1000 \mathrm{~h}$ of exposure in training and matches.

Descriptive statistics were calculated for all outcome variables. Differences between the groups were investigated using the one-way analysis of variance (ANOVA). When a significant $\mathrm{F}$ ratio was obtained, the Bonferroni post-hoc test was used to assess the differences among the groups. Cohen's d was calculated as a measure for interpreting the scores. An effect size of approximately 0.20 was considered small, 0.50 moderate or 0.80 large (16). Chi-square test was carried out to value the difference among injury frequencies observed among the three maturity groups. Statistical significance was determined as $\mathrm{p}<0.05$. The software used to carry out the statistical analyzes was STATA (16.1. StataCorp, College Station, Texas, USA).

\section{RESULTS}

The original cohort consisted of 350 soccer players. Of these, 209 players were excluded (51 players for U13, 4 players for U14 and 7 players for U15) because they had no anthropometric measurement taken to estimate PHV or because their PHV was not within the target stated above or an in-season transfer to another club. The remaining 141 players were observed for the season 2018/2019 (figure 1).

During the period of data collection, 83 injuries were recorded. Most of the injuries were recorded in the lower limb $(77 \%)$ (figure 2). The most common injuries were joint/ligament injuries (36\%) and muscle injuries (33\%); followed by fracture/bone stress $(13 \%)$; contusions and hematomas $(6 \%)$; concussion/nerve injuries (4\%); wound/ laceration $(2 \%)$; while $6 \%$ were classified as other injuries (figure 3). Across all groups, the overall exposure to football was 25214 hours (22388 training hours and 2826 match hours). The mean injury incidence for the total cohort was 3.29 injuries per 1000 hours (0.83 injuries per 1000 hours during matches; 2.46 injuries per 1000 hours during trainings). On a total of 83 injuries, 63 were traumatic and 20 were overuse injuries; 62 injuries occurred in training and 21 in matches. There was a total of 2901 lost days. 


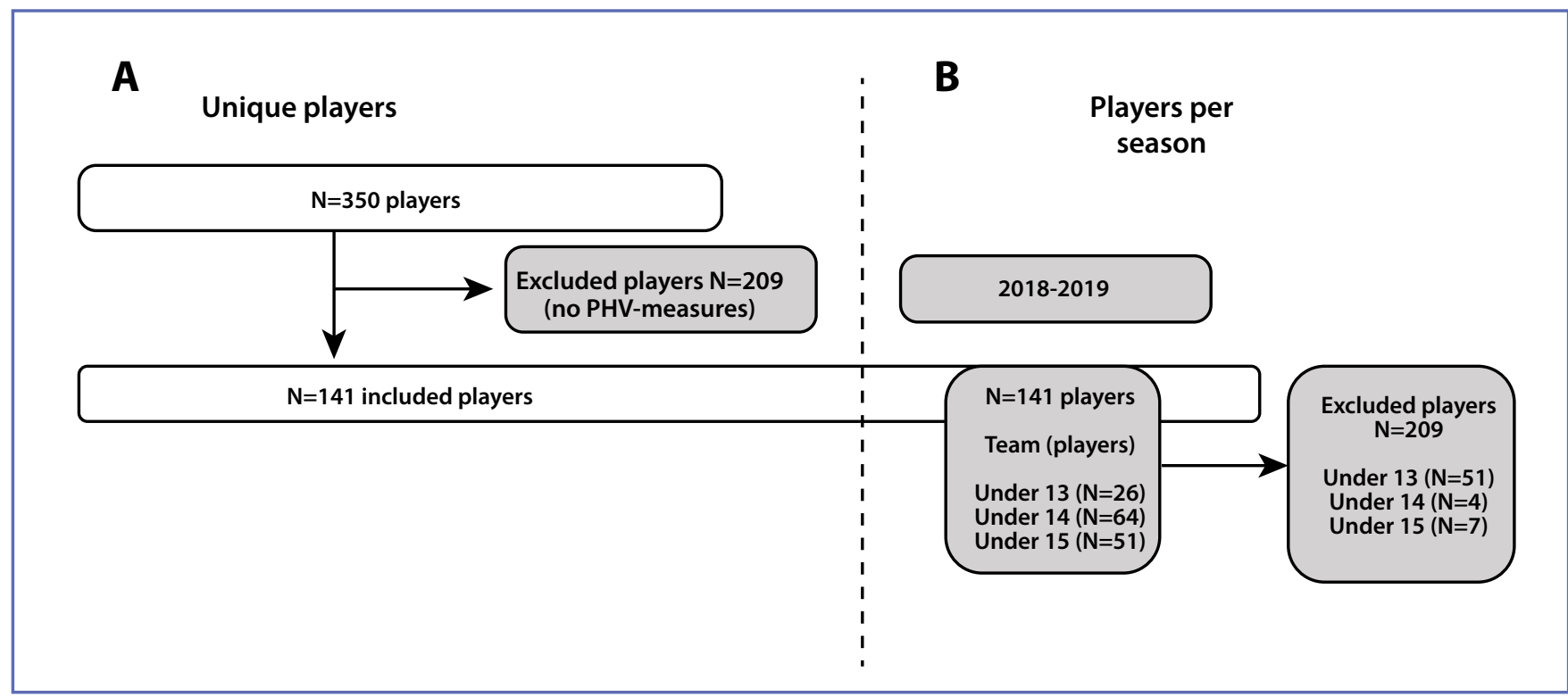

Figure 1. (A) Flowchart of inclusion and exclusion and numbers of observed players for the season 2018/2019. 209 players were excluded because they had no anthropometric measurement taken to estimate PHV or because their PHV was not within the target stated above or an in-season transfer to another club. (B) Numbers of observed players for the season 2018/2019 and per team. For U13, 51 players were exclude; for U14, 4 players were excluded and for U15, 7 players were excluded.

As regards age groups, the category where most of the injuries occurred was U13 (81\% of the sample suffered injuries); followed by U15 (63\%) and finally by U14 (47\% of the sample was injured). Chi square test showed a statistically significant differences in injuries frequencies between the three age groups categories $\left(\chi^{2}=9.2686 ; \mathrm{p}=0.010\right)$.

Considering the subjects according to their maturity status, the athletes at PHV presented the highest incidence of injury $(56 \%)$, followed by subjects in Post-PHV phase $(48 \%)$ and then by subjects in Pre-PHV (45\%); Chi square test did not show statistically significant differences in injuries frequencies between the three groups $\left(\chi^{2}=1.4677 ; \mathrm{p}=0.480\right)$.

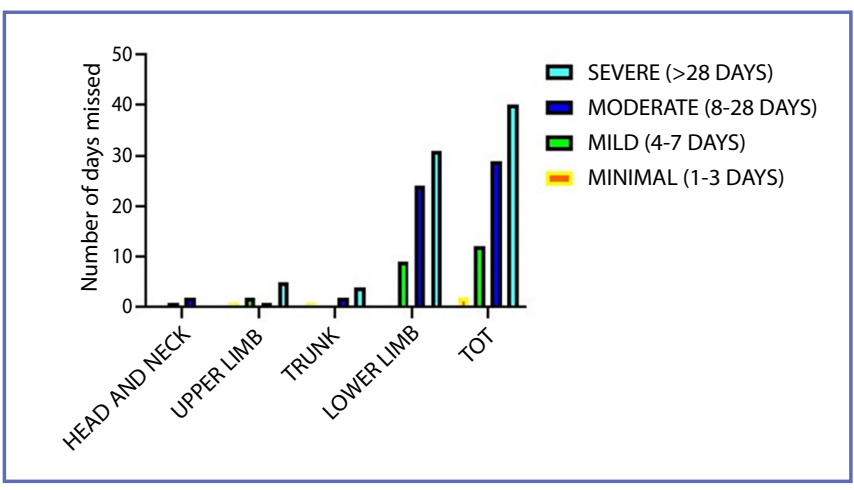

Figure 2. Injury location and severity in the 3 periods around PHV.

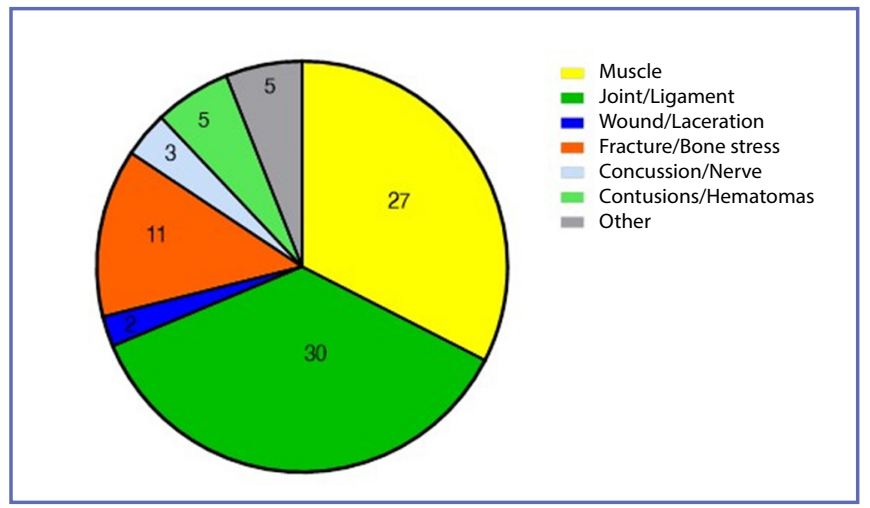

Figure 3. Type of injuries in the 3 periods around PHV.

Traumatic injury incidence, overuse injury incidence, training injury incidence, match injury incidence, missed days due to injuries and mean hours of exposure in the athletes in the three-maturity status are reported in table $\mathbf{I}$.

Traumatic injury showed a tendency to increase from the year before PHV to the year of PHV, after this period a decrease can be observed, without any significant differences among groups. The effect size between Pre-PHV and PHV, PHV and Post-PHV, Pre-PHV and Post-PHV was small (table I and figure 4). 
Table I. Means scores ( \pm standard deviations), effect size, f-values and $p$-values for traumatic injuries, overuse injuries, training injuries, match injuries, days missed due to injuries and mean of hours exposure in talented soccer players before, during and after peak height velocity.

\begin{tabular}{|c|c|c|c|c|c|c|c|c|c|c|c|}
\hline & \multicolumn{5}{|c|}{ Means and standard deviations } & \multicolumn{3}{|l|}{ Cohen's d } & \multicolumn{3}{|c|}{ Post-Hoc Bonferroni } \\
\hline & $\begin{array}{l}\text { Pre-PHV } \\
(\mathrm{n}=23)\end{array}$ & $\begin{array}{l}\text { PHV } \\
(\mathrm{n}=45)\end{array}$ & $\begin{array}{l}\text { Post-PHV } \\
(\mathrm{n}=15)\end{array}$ & $\mathrm{FF}$ & $\mathrm{pp}$ & $\begin{array}{l}\text { Pre-PHV } \\
\text { vs PHV }\end{array}$ & $\begin{array}{l}\text { PHV } \\
\text { vs Post-PHV }\end{array}$ & $\begin{array}{l}\text { Pre-PHV } \\
\text { vs Post-PHV }\end{array}$ & $\begin{array}{l}\text { PHV } \\
\text { vs Pre-PHV }\end{array}$ & $\begin{array}{l}\text { Post-PHV } \\
\text { vs Pre-PHV }\end{array}$ & $\begin{array}{l}\text { Post-PHV } \\
\text { vs PHV }\end{array}$ \\
\hline $\begin{array}{l}\text { Traumatic } \\
\text { injury } \\
\text { incidence }\end{array}$ & $3.4 \pm 7.2$ & $3.9 \pm 5.9$ & $2.4 \pm 5.2$ & 00.62 & 00.54 & 0.07 & 0.26 & 0.16 & 1.00 & 0.87 & 0.81 \\
\hline $\begin{array}{l}\text { Overuse } \\
\text { injury } \\
\text { incidence }\end{array}$ & $1.4 \pm 4.5$ & $1.4 \pm 4.9$ & $1.1 \pm 2.6$ & 00.08 & 00.93 & 0.00 & 0.08 & 0.09 & 1.00 & 1.00 & 1.00 \\
\hline $\begin{array}{l}\text { Training } \\
\text { injury } \\
\text { incidence }\end{array}$ & $3.4 \pm 6.2$ & $4.9 \pm 7.6$ & $3.4 \pm 6.2$ & 00.99 & 00.37 & 0.22 & 0.22 & 0.01 & 0.660 & 1.00 & 0.88 \\
\hline $\begin{array}{l}\text { Match } \\
\text { injury } \\
\text { incidence }\end{array}$ & $17.1 \pm 50.6$ & $6.4 \pm 18.4$ & $8.1 \pm 33.0$ & 11.58 & 00.21 & 0.31 & 0.07 & 0.20 & 0.25 & 0.76 & 1.00 \\
\hline $\begin{array}{l}\text { Days } \\
\text { missed }\end{array}$ & $15.1 \pm 24.4$ & $23.3 \pm 36.7$ & $7.9 \pm 14.6$ & 33.23 & $00.04 *$ & 0.25 & 0.48 & 0.34 & 0.39 & 0.87 & $0.04 *$ \\
\hline Exposure & $134.6 \pm 43.9$ & $158.9 \pm 70.3$ & $176.8 \pm 63.3$ & 4.86 & $0.01 *$ & 0.40 & 0.26 & 0.81 & 0.09 & $0.01 *$ & 0.52 \\
\hline
\end{tabular}

$* \mathrm{p}<0.05$.

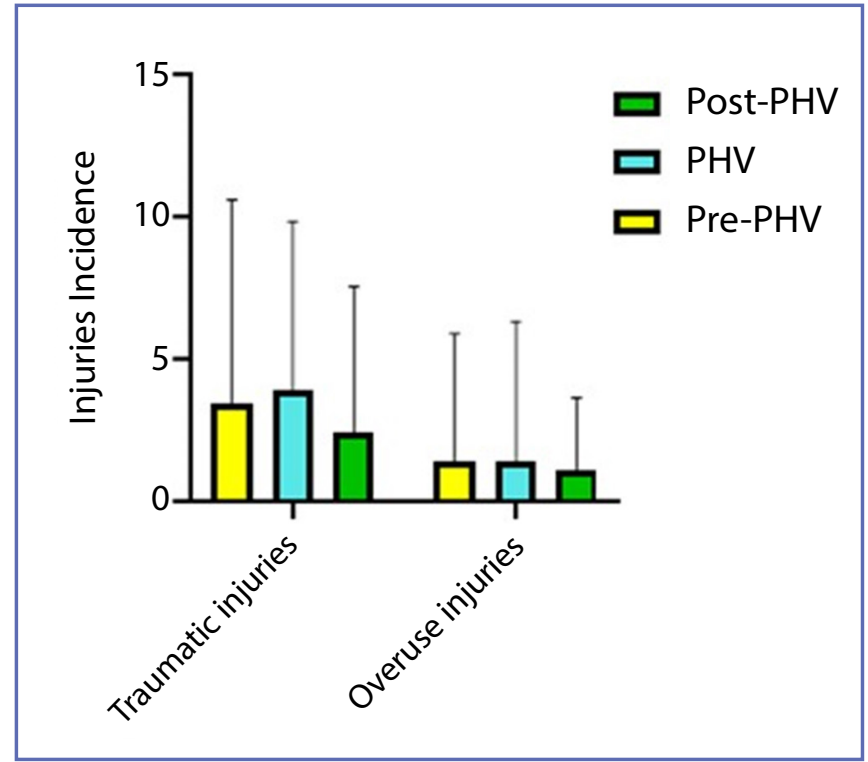

Figure 4. Means and standard deviations for traumatic and overuse injuries incidence per player in talented youth soccer players.

Overuse injuries incidence remained constant until PHV, and then decreased in the year after PHV. The differences between the groups were not significant (table I). Furthermore, functional overload trauma between Pre-PHV and PHV, PHV and Post-PHV, Pre-PHV and Post-PHV showed a small effect size (figure 4).

Training injury incidence per player showed an increase from the year before PHV to the year of PHV, period in which it reached its peak, and after which it decreased. No statistically significant differences were found; moreover, the differences between Pre-PHV and PHV, PHV and Post-PHV, Pre-PHV and Post-PHV showed a small effect size (table I and figure 5). Match injury incidence per player decreased from the year before PHV to the year of PHV; after this period, an increase was observed; also, in this case; no statistically significant differences were observed. Furthermore, injuries in matches between Pre-PHV and PHV, PHV and Post-PHV, Pre-PHV and Post-PHV showed a small effect size (table I and figure 5).

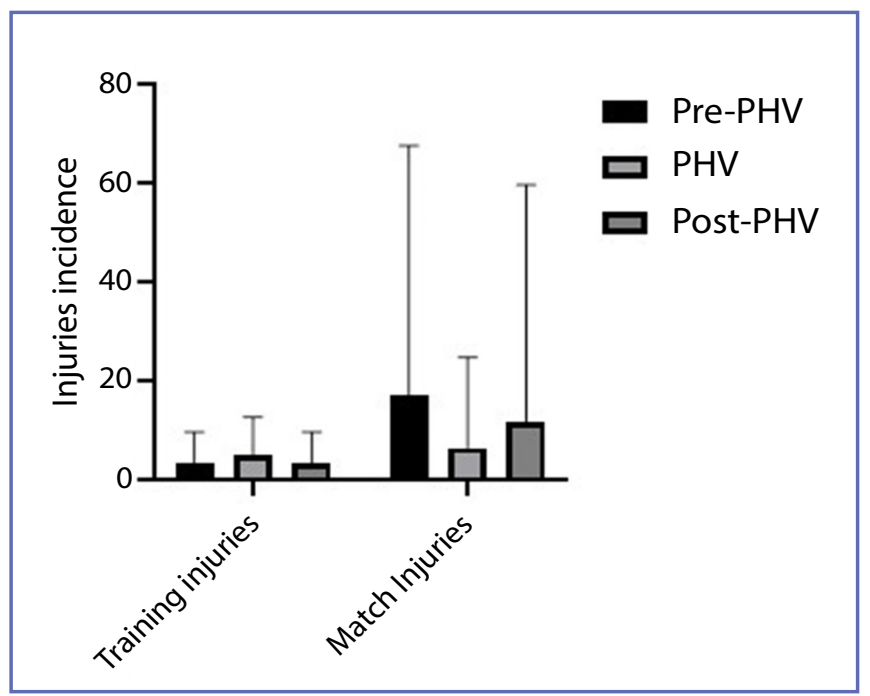

Figure 5. Means and standard deviations for training and match injuries incidence per player in talented youth soccer players. 
Days missed due to injury showed an increase up to PHV, and then a considerable decrease in the year after PHV; the difference among groups were statistically significant and Post-hoc tests revealed that days missed due to injury were significantly higher in the year of PHV than in the year after PHV (table I and figure 6). The effect size regarding this type of injuries between Pre-PHV and PHV, Pre-PHV and Post-PHV was small, instead the effect size between PHV and Post-PHV was moderate.

The Post-PHV group recorded the largest mean exposure with $176.78 \pm 63.33$ hours (table $\mathbf{I}$ and figure 7 ). The mean of exposure showed an increase from the year before PHV to the year after PHV; furthermore, statistically significant differences were found among these groups $(p=0.0089)$. Post-hoc tests revealed that mean of exposure was significantly higher in the year after PHV than in the year before PHV, $\mathrm{p}=0.010$. The mean of exposure between Pre-PHV and PHV showed a moderate effect size; the effect size between PHV and PostPHV was small; instead, the effect size between Pre-PHV and Post-PHV was large (table I).

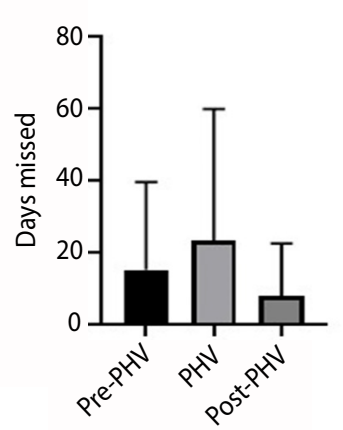

Figure 6. Number of days missed in the 3 periods around PHV (bar represent standard deviation).

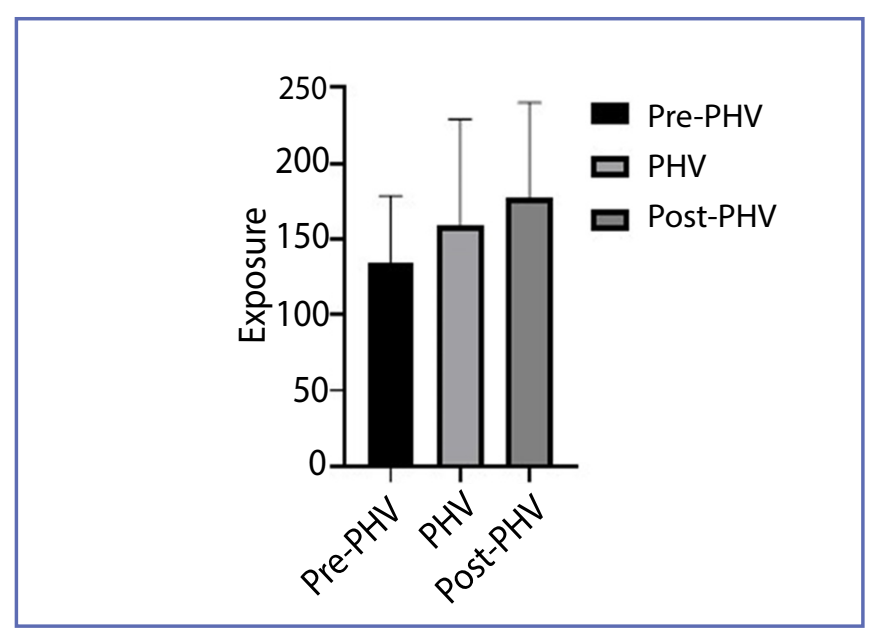

Figure 7. Hours of exposure in the 3 periods around PHV (bar represent standard deviation).

\section{DISCUSSION}

The aim of the present study was to investigate how maturity status (pre-PHV, PHV, post-PHV) influenced injury risk in Italian élite football players. To our knowledge, there are no data regarding Italian young player according to this aspect. In addition, the effects of maturity timing on injury risk are still unclear regarding how maturity status influence injury risk.

We considered the differences in traumatic and overuse injuries, as well as the incidence in training and match injury before, during and after the peak height velocity (PHV), which represents the period of maximal rate of growth.

The percentage variation in injury incidence between the Pre-PHV and the PHV in our study amounted to $29 \%$ and is in line with what reported by Van der Sluis et al. (2013) and Bult et al. (2018), which reported an amount of $37 \%$ and $26 \%$ respectively, while it considerably differed from the results of Johnson et al. (2019) (115\%). The part of the body more susceptible to injuries was the lower limb; this is consistent with other studies regarding youth soccer from different countries $(5,6)$.

The most common types of injury in this study were muscle injuries; a finding similar to the results obtained by Price $e t$ al. (2004), Le Gall et al. (2006) on elite English and French youth football players respectively $(11,17,18)$.

Considering age groups, significant differences were observed between groups, but without a specific trend: the highest incidence was reported in U13, followed by U15 and finally by U14.

Regarding the state of maturity, it was possible to find a tendency to the increase in the incidence of injuries during the PHV, even if not significant. The higher incidence at PHV was reported also by other authors $(6,19)$. According to Towlson et al. (2020) during adolescent growth spurt, boys show a rapid growth (also between 7 and 12 $\mathrm{cm}$ per year), which may partially explain the phenomenon "adolescent awkwardness," whereby the trunk and lower limb length have increased but soft tissues have yet to adapt to the size and weight of the frame, causing abnormal movement mechanics that negatively impact performance. This rapid change in musculoskeletal structure and apparent lag time to adequate relative strength is individually variable based on maturity tempo, which likely corresponds to a variation in readiness to perform and, by inference, to vulnerability to injuries.

Taking into account the specific nature of injuries, traumatic injury and overuse injuries did not show a significant difference among the three maturity groups. Traumatic injury incidence showed a tendency to increase from the year before PHV to the year of PHV, while after this 
period a decrease was observed; overuse injury incidence remained constant until PHV, after which a decrease was recorded. The result regarding traumatic injury and overuse injury were greater from what reported by van der Sluis et al. (2013), even if they did not report any significant difference for these types of injuries, too.

It should be considered that traumatic injuries may be related to factors such as, but not limited to, tendon maturity, reduced joint stiffness, decreased movement efficiency and decreased bone density. On the other hand, overuse injuries, can be attributed to disproportionate development of skeletal maturity in relation to muscle development (20). These maturation-dependent differences in injury risk should be a point of attention for practitioners, with particular regard to the highly demanding mechanical loading of training practices and intensified bouts of match-play often experienced during match-format football. Training injury showed a tendency to increase at PHV too, while match injury tended to show higher incidence in pre-PHV. Injury rate was considerably higher during matches (6.6-17.1 injuries per $1000 \mathrm{~h}$ ) than during training (3.4-4.9 injuries per $1000 \mathrm{~h}$ ), with the majority of injuries being traumatic in nature. The incidence both in training and in matches injuries recorded in our study is comparable to that observed by Le Gall et al. (2006) on elite French youth football players (17).

The general tendency to the increase of injuries at PHV found in the present study highlights the increased vulnerability of athletes at this stage, as demonstrated by other authors. This has been reconducted to a functional overload that acts on a bone tissue and on the myo-tendon complex, both not yet fully developed, which are not able to withstand such high shear and compression forces, leading to fractures and muscle injuries $(8,21)$. Regarding bone tissue, the acquisition of bone mineral content (BMC) and bone mineral density (BMD) occurs during PHV, this osteogenic reorganization and remodelling leads to a greater risk of both traumatic and overuse injuries during this state of maturity. Regarding the myo-tendon complex, the increase in terms of volume and strength is recorded approximately at the PHV. This means that the tissue is particularly susceptible to trauma in this phase, not being able to deliver sufficient force instead of what it would be at Post-PHV; alongside this aspect, low joint stiffness and reduced neuromuscular efficiency leads to greater exposure to both acute and chronic injuries (21).

The days missed due to injuries in talented youth soccer players were significantly higher in the athletes at PHV, who significantly differed from post-PHV athletes. These results are in accordance with those of van der Sluis et al. (2014), even if in their study the differences were not significant. These suggest how during the PHV the injuries are more severe, causing more days of absence from training and/or competition. In this period of growth, the athletes are more susceptible and less receptive to recovery.

The rapid growth and, as a consequence, the period around PHV have been associated with an increased risk of injury in elite youth athletes (22). This has been interpreted as being due to the reduction of the concentration of bone mineral, increased tensile forces on vulnerable muscle attachments, decreased neuromuscular control and reduced flexibility $(4,8,9,23)$.

There are various possible reasons for an increased injury occurrence and burden at PHV. Firstly, during PHV the vulnerability of bodily tissues increases, including changes to muscle-tendon junctions, bone-tendon junctions, ligaments, growth cartilage and bone density $(9,23)$. This could be due to the many changes in size, shape and function that accompany the pubertal growth spurt $(8,24,25)$. The mean of hours of exposure grows linearly from Pre-PHV to Post-PHV, showing statistically significant differences in the Pots-PHV group compared to the Pre-PHV group.

It is to consider that the athletes in the Pre-PHV group are likely to be those who belonged to the youngest category (U13); while the athletes who are in the Post-PHV are those who belong to the category of the oldest (U15), which also presented a higher hour of exposure. The mean of hours of exposure increased linearly from Pre-PHV to Post-PHV, recording statistically significant differences.

The strength of this study was the accuracy with which musculoskeletal injuries were tracked and determined during the study. This made it possible to evaluate and study with greater precision and accuracy the relationships between the risk of injuries and the state of maturity in young elite athletes. The analyzes show that the key factor in reducing the incidence of accidents is to individualize the volume of work. This would help reduce the risk of injury and maximize physical performance. The hope for the theft will be to develop working strategies that take into account the biological maturity, raising awareness, moreover, a proper work by professionals in this field. However, a limitation is represented by the numerosity and cross-sectional nature of the sample.

In conclusion, the results of this study on young Italian football players confirm the overall increased vulnerability of the athletes in the PHV period. To try to limit injuries, training programs should be calibrated on the state of maturity and not on the chronological age of the group. As the chronological age groups increase, the external training load increases. The same training stimulus can improve performance in one player, maintain performance in another and cause injury to a third player. The same considerations could be for applied to playing time: the total distance, the high and very high 
intensity distance that players cover increases with increasing age, and to acceleration, maximum running speed and repeated sprinting skills.

Further research is, however, warranted to confirm this speculation, moreover longitudinal. This could allow to follow the athletes in time, highlighting with greater detail the criticalities.

\section{REFERENCES}

1. Gonçalves Arliani G, Schmidt Lara PH, Costa Astur D, Pedrinelli A, Pagura JR, Cohen M. Orthopaedics injuries in male professional football players in Brazil: a prospective comparison between two divisions. Muscles Ligaments Tendons J 2017;7(3):524-31.

2. Jacobsson J, Timpka T, Kowalski J, et al. Injury patterns in Swedish elite athletics: Annual incidence, injury types and risk factors. Br J Sports Med 2013;97(15):941-52.

3. Pfirrmann $D$, Herbst $M$, Ingelfinger $P$, Simon $P$, Tug $S$. Analysis of injury incidences in male professional adult and elite youth soccer players: A systematic review. J Athl Train 2016;51(5):410-24.

4. Malina RM, Bouchard C, Bar-Or O. Growth, Maturation, and Physical Activity. J Biosoc Sci 1993;25(2):281-3.

5. Van Der Sluis A, Elferink-Gemser MT, Coelho-E-Silva MJ, Nijboer JA, Brink MS, Visscher C. Sport injuries aligned to Peak Height Velocity in talented pubertal soccer players. Int J Sports Med 2014;35(4):351-5.

6. Materne O, Farooq A, Johnson A, Greig M, McNaughton L. Relationship between injuries and somatic maturation in highly trained youth soccer players. In Res Sci Soccer II 2016;1(1):182-92.

7. Rommers N, Rössler R, Goossens L, et al. Risk of acute and overuse injuries in youth elite soccer players: Body size and growth matter. J Sci Med Sport 2020;23(3):246-51.

8. Hawkins D, Metheny J. Overuse injuries in youth sports: Biomechanical considerations. Med Sci Sports Exerc 2001;33(10):1701-7.

9. Van Der Sluis A, Elferink-Gemser MT, Brink MS, Visscher C. Importance of peak height velocity timing in terms of injuries in talented soccer players. Int J Sports Med 2015;36(4):327-32.

10. Fuller CW, Ekstrand J, Junge A, et al. Consensus statement on injury definitions and data collection procedures in studies of football (soccer) injuries. Br J Sports Med 2006;16(2):83-92.

11. Le Gall F, Carling C, Reilly T, Vandewalle H, Church J, Rochcongar P. Incidence of injuries in elite French youth soccer players: A 10-season study. Am J Sports Med 2006;34(6):928-38.

12. Jackowski SA, Erlandson MC, Mirwald RL, et al. Effect of maturational timing on bone mineral content accrual from childhood to adulthood: Evidence from 15years of longitudinal data. Bone 2011;48(5):1178-85.

13. Padulo J, Oliva F, Frizziero A, Maffulli N. Muscles, Ligaments and Tendons Journal - Basic principles and recommendations

\section{ACKNOWLEDGMENTS}

The authors would like to thank all the participants in this research.

\section{CONFLICT OF INTERESTS}

The authors declare that they have no conflict of interests.

in clinical and field Science Research: 2018 update. Muscles Ligaments Tendons J 2018;8(3):305-7.

14. Mirwald RL, Baxter-Jones ADG, Bailey DA, Beunen GP. An assessment of maturity from anthropometric measurements. Med Sci Sports Exerc 2002;34(4):689-94.

15. Toselli S, Merni F, Campa F. Height prediction in elite Italian rugby players: A prospective study. Am J Hum Biol 2019;31(5):e23288

16. Cohen J. Statistical power analysis for the behavioural sciences. New Jersey; Lawrence Erlbaum Associates 1988.

17. Le Gall F, Carling C, Reilly T. Biological maturity and injury in elite youth football. Scand J Med Sci Sport 2007;17(5):564-72.

18. Price RJ, Hawkins RD, Hulse MA, Hodson A. The Football Association medical research programme: An audit of injuries in academy youth football. Br J Sports Med 2004;38(4):466-71.

19. Bult HJ, Barendrecht M, Tak IJR. Injury Risk and Injury Burden Are Related to Age Group and Peak Height Velocity Among Talented Male Youth Soccer Players. Orthop J Sport Med 2018;6(12):2325967118811042.

20. Towlson C, Salter J, Ade JD, et al. Maturity-associated considerations for training load, injury risk, and physical performance in youth soccer: One size does not fit all. J Sport Heal Sci 2020;00:1-10.

21. Jackowski SA, Faulkner RA, Farthing JP, Kontulainen SA, Beck TJ, Baxter-Jones ADG. Peak lean tissue mass accrual precedes changes in bone strength indices at the proximal femur during the pubertal growth spurt. Bone 2009;44(6):1186-90.

22. Johnson A, Doherty PJ, Freemont A. Investigation of growth, development, and factors associated with injury in elite schoolboy footballers: Prospective study. BMJ 2009; 338:b490.

23. Faulkner RA, Davison KS, Bailey DA, Mirwald RL, BaxterJones ADG. Size-corrected BMD decreases during peak linear growth: Implications for fracture incidence during adolescence. J Bone Miner Res 2006;21(12):1864-70.

24. Aiyegbusi AI, Owoeye IO, Balogun OJ, Fapojuwo OO, Akinloye OA. Prevalence of achilles tendinopathy and associated selected intrinsic risk factors among nigerian footballers. Muscles Ligaments Tendons J 2021;11(1):118-27.

25. Iatridou G, Dionyssiotis Y, Papathanasiou J, Kapetanakis S, Galitsanos S. Acute effects of stretching duration on sprint performance of adolescent football players. Muscles Ligaments Tendons J 2018;8(1):37-42. 